\title{
Ecological stages of the Venice Lagoon analysed using landing time series data
}

\author{
Simone Libralato ${ }^{\mathrm{a}, \mathrm{b}, *}$, Fabio Pranovi ${ }^{\mathrm{a}}$, Saša Raicevich ${ }^{\mathrm{a}, \mathrm{b}}$, Filippo Da Ponte ${ }^{\mathrm{a}}$, \\ Otello Giovanardi ${ }^{b}$, Roberto Pastres ${ }^{c}$, Patrizia Torricelli ${ }^{a}$, Danilo Mainardi ${ }^{a}$ \\ a Dipartimento di Scienze Ambientali, Università Ca' Foscari, 2737/B Castello, 30122 Venice, Italy \\ ${ }^{\mathrm{b}}$ Istituto Centrale per la Ricerca Scientifica e Tecnologica Applicata al Mare, ICRAM, Chioggia (VE), Italy \\ ${ }^{\mathrm{c}}$ Dipartimento di Chimica Fisica, Università Ca' Foscari, 2137 Dorsoduro, 30123 Venice, Italy
}

Received 31 December 2002; accepted 19 May 2004

Available online 9 August 2004

\begin{abstract}
The time series of landings in the Venice Lagoon from 1945 to 2001 were analysed with the aim of explaining the ecosystem changes occurred. The comparative analysis of the total landings and mean Trophic Level (mTL) time series allowed to identify four different stages in the lagoon ecosystem. The first period, from 1945 to 1973, was characterised by increasing trends in the landings and their mTL. The second one, from 1974 to 1989, showed a decrease in the landings but still an increase in the mTL. The third period, from 1990 to 1998, had again a positive trend in the landings, but the mTL showed a sharp decline. After 1998, a slight decreasing trend in both mTL and landings was observed: the analyses of the artisanal fishery landings only date back to 1995 this effect. The presence of four distinct periods was also confirmed by the analysis of the trends of other indices estimated using landings data: the Fishing in Balance index (FiB), the Trophic Efficiency (TE) and the Pelagic on Demersal landings ratio (P/D). In the first period, the increasing fishing pressure, along with no evidence of ecosystem crisis, suggested that an increased nutrient discharge was supporting it; analogously, the bottom-up effects had driven the dynamics of the ecosystem also in the second period, when the decrease in nutrient loads caused a shift of the primary producers from planktonic to macrobenthic. The spreading of the Manila clam, a non-native species, and the development of its massive mechanical exploitation have been the main forces driving the ecosystem during the third period, for which, however, no signs of crises were detected. The fourth period showed evidence of the "fishing down the food web" effect. Possible causes of such an effect were investigated and allowed us to conclude that not overfishing, but the effects of mechanical harvesting of the Manila clam had caused relevant impacts on habitat and benthic communities, concluding that the present level of exploitation of the stock of Manila clam is not sustainable in the long term. Our findings were also compared with the general evolution of enclosed seas, subjected to high nutrient loads, fishing pressure and invasion by non-native species.
\end{abstract}

(C) 2004 Elsevier B.V. All rights reserved.

Keywords: Fishery data; Trophic levels; Transfer efficiency; Manila clam; Eutrophication; Venice Lagoon

* Corresponding author. Dipartimento di Scienze Ambientali, Università Ca' Foscari, 2737/B Castello, 30122 Venice, Italy. Tel.: +39-41-2348632; fax: +39-41-2348495.

E-mail address: libral@unive.it (S. Libralato).

\section{Introduction}

One of the main forces driving the changes in marine ecosystems is recognised to be the fisheries. In 
accordance with Pauly et al. (1998), the changes in the composition of landings reflect the changes in structure of the ecosystem: therefore, one can get some insights about the functioning of an ecosystem by studying the landings (quantity) coupled with the information concerning their composition (quality). The latter is evaluated in terms of ecological and energetic characteristics by using the trophic level (TL) of each captured species (Pauly et al., 1998; Pinnegar et al., 2002; Pauly and Palomares, in press).

Fishing is the most widespread exploitation activity of marine resources and can severely affect marine ecosystems both directly and indirectly (Jennings and Kaiser, 1998; Jackson et al., 2001). One of the main effects of the increasing fishing effort is described as Fishing Down the Food Web, FDFW (Pauly et al., 1998): a depletion in top predators and the most susceptible species causes a shift in the composition of the fish community towards faster growing and smaller sized species. As a consequence, these species, which belong to lower trophic levels, become target of the fishing activities. A number of papers (Pauly et al., 1998; Stergiou and Koulouris, 2000; Pauly et al., 2001) showed that the FDFW effect characterizes the trends of worldwide landings as well as those of the landings concerning specific ecosystems.

The advantage of studying the FDFW for having insights on ecosystem changes is that landings data are usually available and the trophic level of each species can then be determined by direct analysis of gut contents (Stergiou and Karpouzi, 2002), isotopes studies (Pinnegar and Polunin, 1999; Pinnegar et al., 2002) and ecosystem modelling (Christensen and Pauly, 1993).

Changes in landings quantity and composition could be the effect of changes in fishing grounds, fishing gears or market-driven shift of the target species that may not be directly related to the fishing effort. Moreover, other kinds of stress agent may induce changes in the ecosystem that can be similar to those produced by overexploitation. The cultural eutrophication, for example, affects the ecosystem structure shortening and simplifying the food webs that show lower mean trophic level and diversity, inducing the dominance of small pelagic planktivorous fish over demersal piscivorous fish (De Leiva Moreno et al., 2000).

Therefore, the simple analysis of temporal dynamics of the mean trophic level and the quantity of landings may not be sufficient enough to discriminate the causes that have induced the observed changes in the ecosystem. The analysis of the driving forces needs to couple other emerging indices, such as the Fishing in Balance (FiB, Pauly et al., 2000a), the Transfer efficiency (TE, Pauly and Palomares, in press) and the Pelagic on Demersal ratio (P/D, Caddy, 2000).

In recent history, the Venice Lagoon ecosystem was exposed to many anthropogenic disturbances such as the discharge of pollutants and nutrients from the industrial area and the drainage basin, the discharge of urban wastes from the city of Venice (Cossu and De Fraja Frangipane, 1985), and the increase of the exploitation of the biological resources. To this regard, the Venice Lagoon has been exploited for centuries. This traditional fishing activity, carried out mainly by means of static gears, showed an increase in the fishing effort since the end of the Second World War (Mozzi, 1967).

The last decade had seen the exponential development of the Manila clam exploitation. The non-native species Manila clam, Tapes philippinarum, was introduced in the lagoon in 1983 (Cesari and Pellizzato, 1985). In 1999, the landings reached $6 \times 10^{7} \mathrm{~kg}$, more than half of the entire Italian clam production (ASAP, 1999; Provincia di Venezia, 1999). At present, the mechanical clam harvesting is carried out by means of high impacting gears, which represents one of the main causes of environmental stress (Pranovi and Giovanardi, 1994; Da Ponte et al., 2001; Libralato et al., 2002).

In this paper, we present the first attempt at detecting the ecological stages of the Venice Lagoon by using landings data. Such an application is particularly appropriate, since the lagoon is a semi-enclosed basin and, therefore, it is possible to accurately assess the extension of the fishing grounds. In addition, it was possible to obtain reliable estimates of the annual landings time series in the lagoon from records of the Venice and Chioggia fish markets.

The main aims of this study are:

- to analyse the modifications in the lagoon ecosystem structure by comparing the time series of landings and their mean trophic level;

- to identify the major forces which had been driving the dynamics of the Venice Lagoon ecosystem for the last 50 years; 
- to evaluate the effects, at an ecosystem level, of the introduction and the mechanical exploitation of the non-native species, Manila clam.

These aims will be achieved through the analysis of the time series of landings from 1945 to 2001 with the methods used for detecting the FDFW (mean trophic level) coupled with the estimation and the analysis of a set of indices (FiB, TE, P/D).

\section{Materials and methods}

\subsection{Area of study}

The Venice Lagoon, with a surface of $550 \mathrm{~km}^{2}$, is the largest salt marsh environment in the Northern Adriatic Sea. The lagoon can be regarded as a semienclosed basin, which exchanges approximately $1.5 \cdot 10^{8} \mathrm{~m}^{3}$ of water with the sea at each tidal cycle through three inlets (DRAIN, 2001). This basin receives freshwater from 24 tributaries, the maximum discharge being $100 \mathrm{~m}^{3} \mathrm{~s}^{-1}$ (DRAIN, 2001).

The Venice Lagoon represents an interesting case study for testing some recent theories concerning the effects of fishing activity and eutrophication on ecosystems. In fact, the basin's limited extension and its well known recent history make it possible to attempt of separating the effects of fishing from those of eutrophication.

\subsection{Data source and preliminary treatment of raw data}

The time series here presented were obtained from the fish markets of Chioggia and Venice, in which all the landings from the lagoon are sold. In order to obtain reliable time series, the raw data were preliminarily treated in order to minimize three possible sources of bias (see Caddy et al., 1998; Pauly et al., 1998; Pauly and Palomares, in press): the produce of the fish-farming activity, the landings concerning the Adriatic sea and the produce which is traded illegally.

The first source of bias can be easily eliminated, since the lagoon landings from aquaculture are directly indicated in the markets data.

As far as the second source is concerned, we minimized it by considering the landings of the marine species only if they were recorded in months in which these species migrate into the lagoon. In order to achieve this goal, the catch composition of the artisanal fishing activity in the lagoon was monitored on the field, thus identifying the periods in which the migrating species are caught in the lagoon (Mainardi et al., 2002).

The bias represented by unreported catches referred mainly to Manila clam landings. In this case, different unofficial sources were used to verify and correct the official ones (Provincia di Venezia, 1999).

As regard to the Manila clam, another correction was introduced to the raw market data, since they are expressed as wet weight. The wet weight data can be used when shellfish represents a small fraction of the total landing, while the shell free wet weight is more indicate when the shellfish fraction is relevant. In the Venice Lagoon, clams proportion ranged within 45$97 \%$ of total landings in the years 1991-2001, so differently from previous studies (Pauly et al., 1998, 2001; Stergiou and Koulouris, 2000), in order to eliminate the contribute of the shell, we transformed the clam wet weight data in shell free wet weight, by assuming an average shell free to wet weight ratio of 0.087 (Solidoro et al., 2000).

\subsection{Computation of the trophic level of landings}

The TL of a species is the average number of passages through the trophic chain from the primary producers and detritus up to a given organism (Lindeman, 1942). In accordance with this definition, the TL is a real number ranging from 2 (detritivorous or herbivorous) up to 5 (large top predators, i.e. tuna and sharks), which is calculated by means of the following expression:

$\mathrm{TL}_{j}=1+\sum_{i} \mathrm{DC}_{i j} \cdot \mathrm{TL}_{i}$

where the $\mathrm{TL}$ of the predator $j, \mathrm{TL}_{j}$, is calculated as a function of the fraction of the preys $i$ in its diet $\left(\mathrm{DC}_{i j}\right)$, and their trophic levels $\left(\mathrm{TL}_{i}\right)$. Using Eq. (1), the TL is computed starting from the herbivorous and detritivorous species, whose preys (primary producers and detritus forms) are assigned TL $=1$, up to all species of the ecosystem (Christensen and Pauly, 1993; Pauly and Palomares, 2000). 
Once the time series of the landings and their composition in terms of species were determined, the TL for each species was computed by using TROPHLAB, a software package purposely built (Pauly et al., 2000b). When the specific data are not available, TROPHLAB supplies standard values of TL for the prey species as a means of estimating the TL of a predator (Pauly et al., 2000b). In the present work, we were able to estimate the TL on the basis of the diet compositions taken from the published data concerning the Venice Lagoon or similar coastal ecosystems. The diet compositions regarding gobies (Zosterisessor ophiocephalus, Pomastoschistus spp.) were estimated using our own data (unpublished data); as regards the Mugilidae, Platichthys flesus and Sprattus sprattus, we used the diet composition taken from "Fishbase" (Froese and Pauly, 2002, www.fishbase.org), while for the other fish species we used already published data (Arias, 1980; Costa et al., 1992; Palomares et al., 1993; Stergiou and Karpouzi, 2002). As far as macrobenthic species are concerned, the coefficients $\mathrm{DC}_{i j}$ were determined using the following criteria: the morphology of the feeding apparatus, the feeding mode and nature. This was done in accordance with the trophic classification and observations made by Fauchauld and Jumars (1979), Desrosiers et al. $(1986,2000)$ and of the findings reported in Sorokin and Giovanardi (1995), which concern mainly the species $T$. philippinarum.

The time series of the mean trophic level of the landings was then computed by means of the following equation (Pauly et al., 1998):

$\mathrm{mTL}_{k}=\frac{\sum_{j} Y_{j k} \cdot \mathrm{TL}_{j}}{\sum_{j} Y_{j k}}$

in which $Y_{j k}$ represents the landing concerning the species $j$ in a given year $k$ and the $\mathrm{mTL}_{k}$ represents the mean trophic level of the landings for that year.

\subsection{Estimation of FiB index and transfer efficiency}

In some instances, the FDFW effect could be the result of fishing management strategies: as an example, the targeting of species with low TL for satisfying market demand would produce a decrease in the mTL of landings that does not represent a signal of compromised health of marine environment. Moreover, also the nutrient enrichment and the changes in the fishing effort could influence the pattern of landings and mean trophic level. Therefore, Pauly et al. (2000a) proposed to use the $\mathrm{FiB}$ in order to assess whether a certain level of exploitation can be sustained by a given marine ecosystem and to detect bottom-up effects (Pauly and Palomares, in press). The FiB is estimated for each year and it takes into account both the landings and their mTL (Pauly et al., 2000a), which are combined in the following expression:

$$
\begin{aligned}
\mathrm{FiB}_{k}= & \log \left(\frac{Y_{k} \cdot\left(\frac{1}{\mathrm{TE}}\right)^{\mathrm{mTL}_{k}}}{Y_{0} \cdot\left(\frac{1}{\mathrm{TE}}\right)^{\mathrm{mTL}_{0}}}\right)=\log \left(\frac{Y_{k}}{Y_{0}}\right) \\
& +\left(\mathrm{mTL}_{k}-\mathrm{mTL}_{0}\right) \cdot \log \left(\frac{1}{\mathrm{TE}}\right)
\end{aligned}
$$

in which $Y_{k}$ and $\mathrm{mTL}_{k}$ represent the total landing and its mTL for the year $k, Y_{0}$ and $\mathrm{mTL}_{0}$ the total landing and its $\mathrm{MTL}$ for the first year of the time series. The $\mathrm{mTL}$ is at the exponent of the inverse of the TE, which is set initially as $10 \%$, found to be the average value by an analysis of a suite of different marine ecosystems (Pauly and Christensen, 1995).

The FiB represents the ratio between the energy required to sustain the fishery landings and the baseline value (the first year of the time series). Therefore, a positive trend in the FiB time series may be caused by an increase in the fishing effort (expanding fisheries) or by an increase in the nutrients availability, which, in turn, leads to an increase in the productivity of the ecosystem and then in the landings (Pauly and Palomares, 2000). It can be noted that FDFW effects lead a decrease in the FiB, which is due to the decrease in both the mTL and the landings.

In accordance with the literature (Pauly et al., 2000a; Pauly and Palomares, 2000), nearly constant values of FiB index over time identify periods during which the fishing pressure and the carrying capacity of the ecosystem have been stable, or that fishing effort has changed accordingly to the changes in the carrying capacity (balanced exploitation).

Therefore, the time series of the FiB could be very useful representing a proper combination of the 
information carried by both landings and mTL, and giving supplemental base for infer in the causes of landings changes (Pauly and Palomares, in press).

Moreover, the periods with balanced exploitation in relation to carrying capacity (evidenced by nearly stable values of $\mathrm{FiB}$ ) allow considering the landing composition as representative of the biological communities. Therefore, landings and mTL can be used to estimate the average TE of the system, which is an indicator of the system status and condition (Pauly and Palomares, in press). When FiB is nearly constant, in fact, one can write together the constant terms in Eq. (3) as:

$K=\frac{\left[\mathrm{mTL}_{0} \cdot \log (\mathrm{TE})-\log \left(Y_{0}\right)-\mathrm{FiB}\right]}{\log (\mathrm{TE})}$

This justifies the linear relationship between the mTL and the logarithm of the landings observed by Pauly and Palomares (in press):

$\mathrm{mTL}_{k}=\frac{1}{\log (\mathrm{TE})} \cdot \log \left(Y_{k}\right)+K$

Eq. (5) can then be used for estimating TE directly from the linear regression of the mTL versus logarithm of landings. Although its use is proposed for periods with strictly balanced exploitation evaluated by means of the FiB calculated with TE equal to $10 \%$ (Pauly and Palomares, in press), rough estimates could be obtained also for periods with slightly balanced exploitation.

\subsection{Estimation of the $P / D$ ratio}

Since the changes in ecosystem structure are related to changes in the trophic relationships, the analysis of the proportional abundance of the trophic groups in the time series of the landings can also convey important information about the evolution of ecosystems. The trophic groups were defined as assemblages of species with similar ecological and trophic characteristics. Therefore, the 19 items found in the market records, and representing species, group of species or same species in different growth stage, were aggregated into 8 trophic groups, as reported in Table 1 .

We used the result of the above classification for computing the pelagic/demersal ratio (P/D), which was estimated as the ratio between the small pelagic species (plankton feeder group) and the piscivores species (predator and benthic groups). The former are positively influenced by nutrient enrichment (Caddy,

Table 1

Composition of landings from the Venice Lagoon and estimated TL

\begin{tabular}{|c|c|c|c|c|}
\hline Group & Scientific name & Common name & Vernacular & Estimated TL \\
\hline \multirow[t]{3}{*}{ Fish predators } & Dicentrarchus labrax & seabass (juveniles) & baicoli & 3.80 \\
\hline & Dicentrarchus labrax & seabass & branzini & 3.80 \\
\hline & Anguilla anguilla & european eel & bisati & 3.50 \\
\hline \multirow[t]{2}{*}{ Fish detritivorous } & Chelon labrosus & grey mullet & boseghe & 2.42 \\
\hline & Mugilidae & mullets & cefali & 2.05 \\
\hline \multirow[t]{3}{*}{ Fish plankton feeders } & Engraulis encrasicolus & European anchovy & acciughe & 3.40 \\
\hline & Sprattus sprattus & sprat & papaline & 3.10 \\
\hline & Atherina boyeri & sand smelt & anguelle & 3.30 \\
\hline \multirow[t]{4}{*}{ Fish benthic } & Platichthys flesus & flounder & passarini & 4.40 \\
\hline & Solea sp. & sole & sogliole & 3.28 \\
\hline & Zosterisessor ophiocephalus & grass goby & go & 3.60 \\
\hline & Pomatoschistus sp. & gobies & marsioni & 3.80 \\
\hline Cephalopods & Sepia officinalis, Loligo vulgaris & cuttlefish and squid & seppie & 4.50 \\
\hline Clams & Tapes philippinarum & Manila clam & caparozzoli & 2.70 \\
\hline \multirow[t]{2}{*}{ Shrimps } & Crangon crangon & common shrimp & schie & 2.80 \\
\hline & Palaemon spp. & prawn & gambareti & 2.80 \\
\hline \multirow[t]{3}{*}{ Crabs } & Carcinus aestuarii & green crab ( $\uparrow$ with eggs) & masanete & 3.40 \\
\hline & Carcinus aestuarii & green crab (moulting stage) & moeche & 3.40 \\
\hline & Carcinus aestuarii & green crab & gransi & 3.40 \\
\hline
\end{tabular}

Sometimes the same species, being exploited at different stage of the life cycle, is reported as different market product (different vernacular). The 19 different products are aggregated into 8 trophic groups. 
1993), while the latter are more affected by the dynamic of the benthic community and are more sensitive to the negative consequences of excessive nutrient enrichment. Therefore, the positive trend over time of $\mathrm{P} / \mathrm{D}$ ratio, which value depends upon both nutrient enrichment and over-exploitation, is more related to the eutrophication (Caddy, 2000; De Leiva Moreno et al., 2000), allowing to distinguish between nutrient loads (carrying capacity) and fishing effort as the possible cause of changes in the landings.

\section{Results}

The specific composition of landings and the estimated TL of each species are reported in Table 1. As one can see from Fig. 1, from 1945 to 1975, the total landings (solid circles), steadily increased from $1.5 \times 10^{6}$ to $5.7 \times 10^{6} \mathrm{~kg} /$ year. This positive trend was followed by an 18 -year phase characterized both by a negative trend and by larger short-term fluctuations. After reaching the minimum in 1992, the landings rose sharply to $7.2 \times 10^{6} \mathrm{~kg}$ in 1999 , which represents the maximum value of the time series, and then decreased to about $5.3 \times 10^{6} \mathrm{~kg}$ in 2001 (all the landings are expressed as shell-free wet weight).

As regards the mTL (Fig. 1, open circles), it showed small fluctuations around the mean value of
3.40 between 1945 and 1960, in spite of the positive trend in the catches. Over the following 30 years, the trend of mTL was characterized by a slight and steady increase: the highest value (3.60) was reached in 1991. In the last decade, the mTL underwent a sharp decrease, due to the increase in the Manila clam landings: the absolute minimum was observed in the 1998, with a value of 2.90 .

The scatter-plot of the mTL versus the landings is presented in Fig. 2. In order to dump the short-term fluctuations, we filtered the time series of the landings and mTL by using a fifth order centred moving average. The fifth order proved to be the best choice in order to have the residuals normally distributed around zero (the K-S, Lilliefors and Shapiro-Wilk tests allowed to reject the hypothesis that the residuals are not normal distributed; as an example ShapiroWilk test gave $W=0.973, p=0.234$ and $W=0.972$, $p=0.214$, respectively, for residuals of mTL and total landings). The filtering process is expected to produce little alterations on the key points in time that, however, does not hamper to obtain rough estimates of periods with in the plot of mTL versus landings. The plot of the total landings (Fig. 2, solid circles) shows clearly that the time series analysed can be divided into four periods: (1) from 1945 to 1973, the trends of the total landings and of their mTL were both positive; (2) from 1974 to 1989 , the trend of the

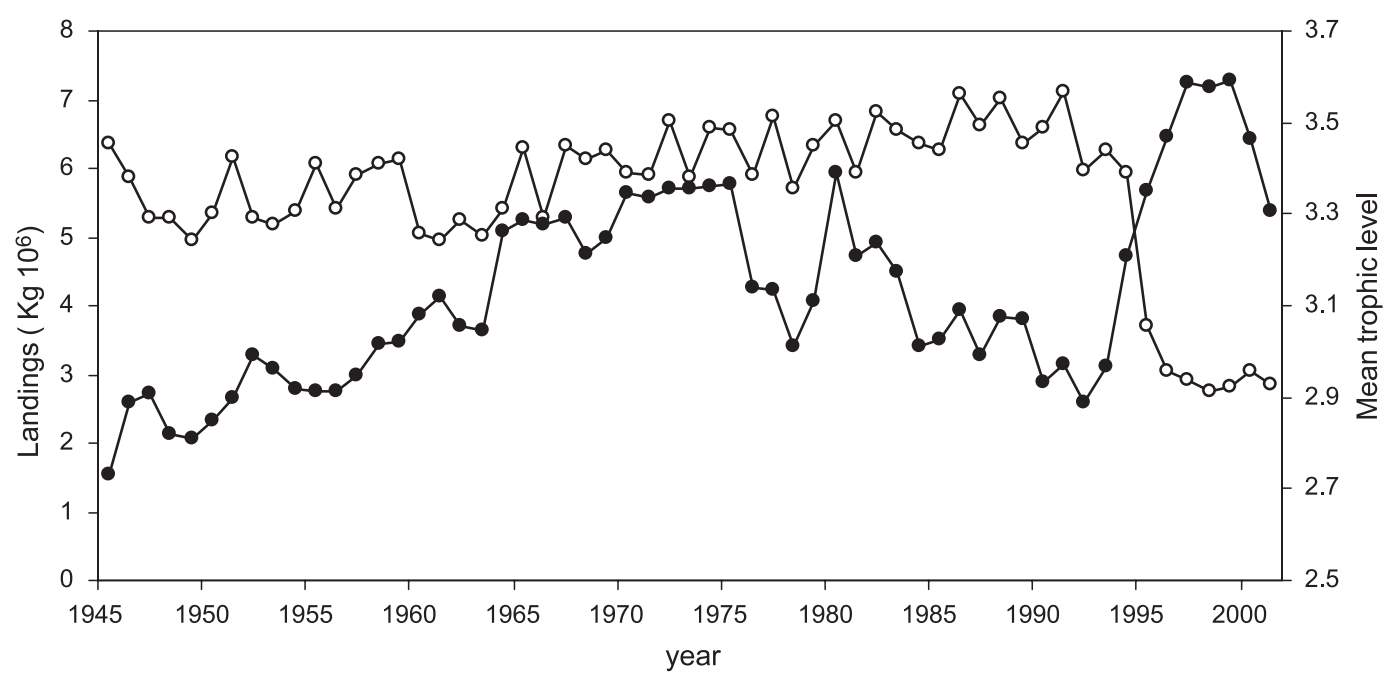

Fig. 1. Total landings (solid circles) and mean trophic level (open circles) of the Venice Lagoon during the period 1945-2001. The landings for the Manila clam (Tapes philippinarum) are expressed as shell free wet weight. 


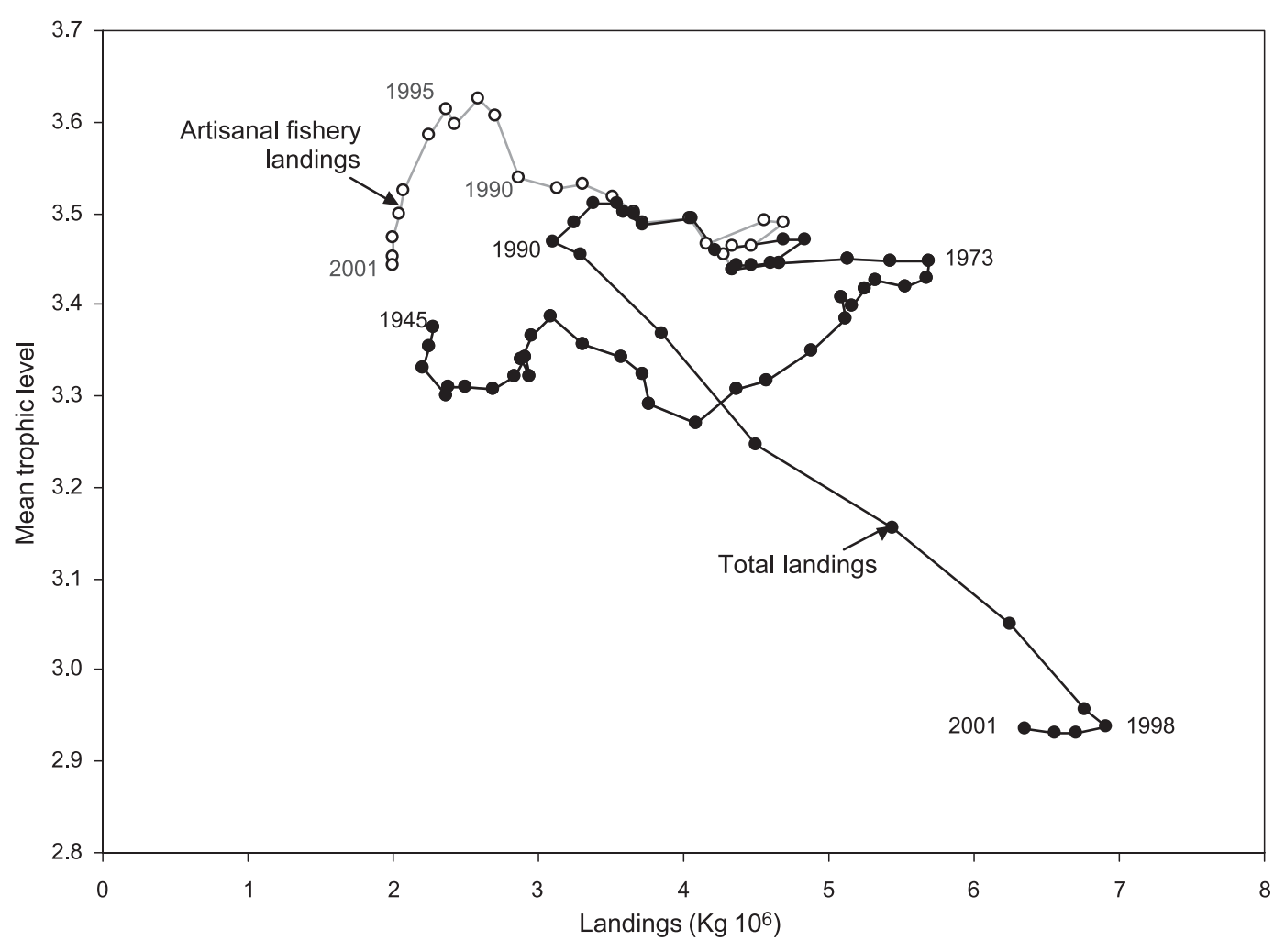

Fig. 2. Relationship between landings and mean trophic level. The total landings, including Manila clam (solid circles), allow to identify four main phases on the history of the catches of Venice Lagoon: the increasing both catches and mTL, from 1945 to 1973; the drop in catches but still increasing mTL, between 1974 and 1989; fast increase of catches and the drop in the mTL, from 1990 to 1998. Excluding Manila clam landings (open circles) the major differences refer to the years from 1993 to 2001 . The effect of the clam fishery in the lagoon ecosystem, measured through the other catches, reveals a "fishing down food web" effect from 1995.

landings was negative whereas the mTL one was slightly positive; (3) from 1990 to 1998, the landings started increasing again while the mTL dropped; (4) after 1998, an incipient backward-bending shape with decreasing catches and mTL (slightly), but not clear conclusion can be taken.

Excluding Manila clam from the total landings allows considering only the artisanal fishery landings (open circles in Fig. 2), which shows major differences in the 1993-2001 period. The use of the artisanal landings is helpful on the understanding the ecosystem dynamics for the period with high exploitation for Manila clam, and it allows better identifying the dynamics in the fourth phase. Using this artisanal landings time series, in fact, a clearer backward-bending shape can be observed since the 1995.
The time series of the FiB index, Fig. 3A, showed an increasing trend accompanied by rather large fluctuations from 1945 to the middle of the 1970s. This index decreases slightly over the next two decades, till 1996, followed by a more marked decrease in the last years of the time series.

The period from 1962 to 1996 was chosen for applying (Eq. (5)), in order to estimate the TE of the idealized linear trophic chain of the system. Since the period does not show a strong "Fishing in Balance", the values of TE obtained would be considered rough estimates. The TE was estimated separately for the three sub-periods identified on the basis of the linear shape of the plot of mTL against logarithm of landings (Fig. 3B). The values obtained for TE were $16.2 \%$ for the years $1962-1973,0.5 \%$ for the years $1974-1989$ and $20.0 \%$ for the years $1990-1996$. 
A
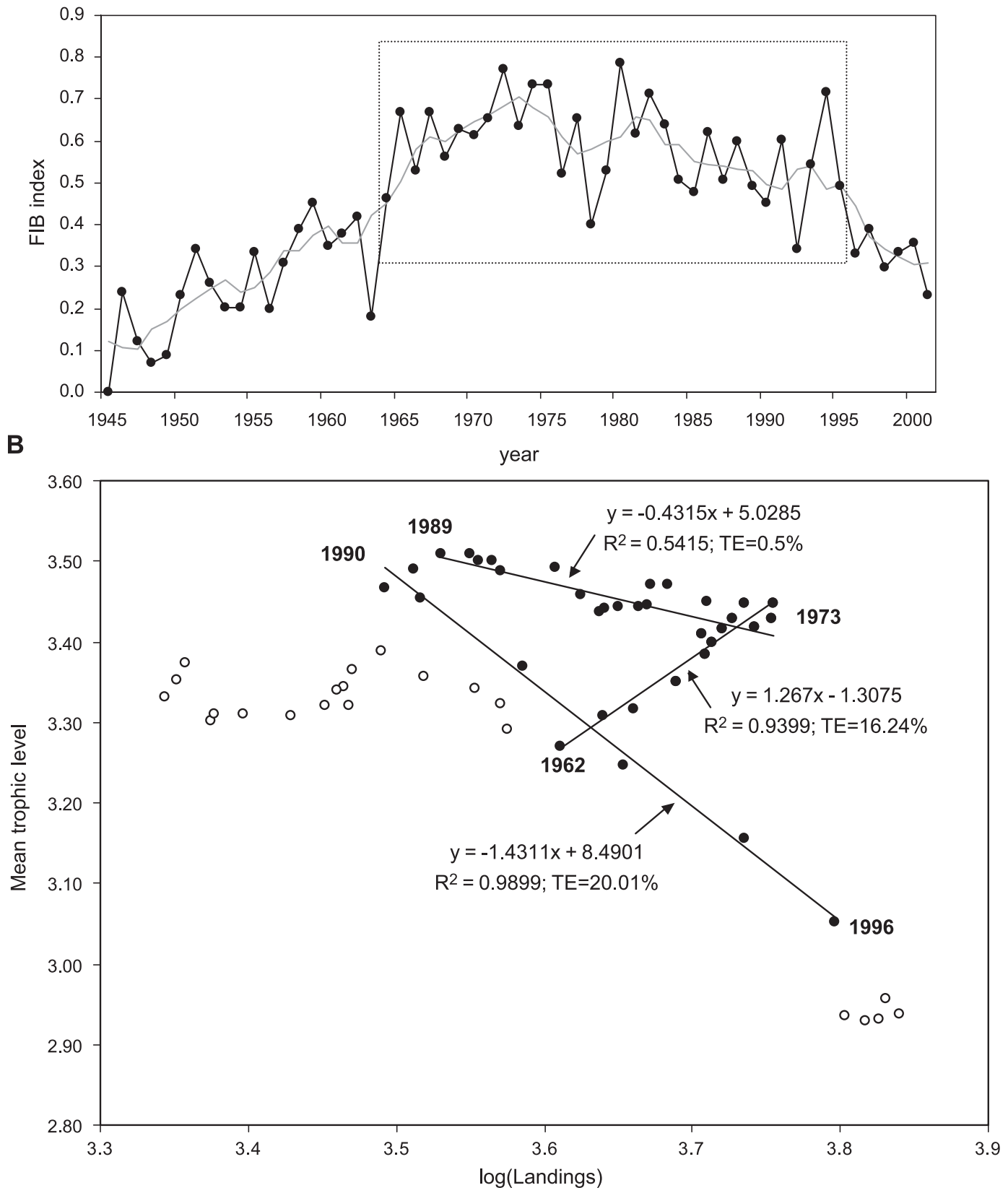

Fig. 3. (A) Time series of the FIB index (points) reported with the fifth order moving average (thick line). The period between 1962 and 1996 (box) corresponds to the years used for estimate the transfer efficiency (TE). (B) Relationships between log landings and mTL for the period 1962-1996. The TE was estimated by the linear regression as $16.2 \%, 0.5 \%$ and $20 \%$ for three sub-periods, respectively, 1962-1973, 19741989 and $1990-1996$. 
The time series of the P/D ratio for the landings of the lagoon from 1945 to 2001 is reported in Fig. 4. From 1945 to 1973, this series shows an increasing trend. After a marked decrease occurred between 1973 and 1976, the P/D ratio fluctuated around 1 until 1995, and then dropped down.

\section{Discussion}

According to some authors (e.g. Caddy et al., 1998; Pauly and Palomares, 2000, in press), both the landings data and TL estimates may be biased and affected by a high degree of uncertainty, which, in turn, may lead to misleading conclusions. In accordance with the recent literature, the two main sources of uncertainty are the diet composition coefficients used for estimating the TL (Polunin and Pinnegar, 2000) and the identification of the fishing area (Pauly and Palomares, in press), while unreported catches appear to be the main source of bias (Watson and Pauly, 2001).

As regards the first problem, Pauly et al. (1998) made it clear that the uncertainties concerning the diet coefficients introduce small errors in the estimations of the mTLs. The identification of the area of influence of the fishing activity, instead, could represent a major source of uncertainty, since establishing a relation between the landings and a specific fishing area is made difficult if the fishermen change the exploited grounds and/or target species. To this regard, the fact that the Venice Lagoon is a semienclosed basin exploited mainly by small scale fishing activities, made it easier to minimize this source of uncertainty.

As regards the bias due to the unreported catches, the market records of the landings were corrected by using different sources of data. Therefore, the time series, which were presented in the previous section, could be confidently used for gaining a better understanding of the evolution of the Venice Lagoon ecosystem over the last 50 years.

\subsection{Can nutrient enrichment counterbalance the effects of an increasing fishing effort?}

The positive trend in the landings and the dynamic of the mTL observed from 1945 to 1973 can be explained both by the increase in the fishing effort and by the nutrient enrichment or by a combination of

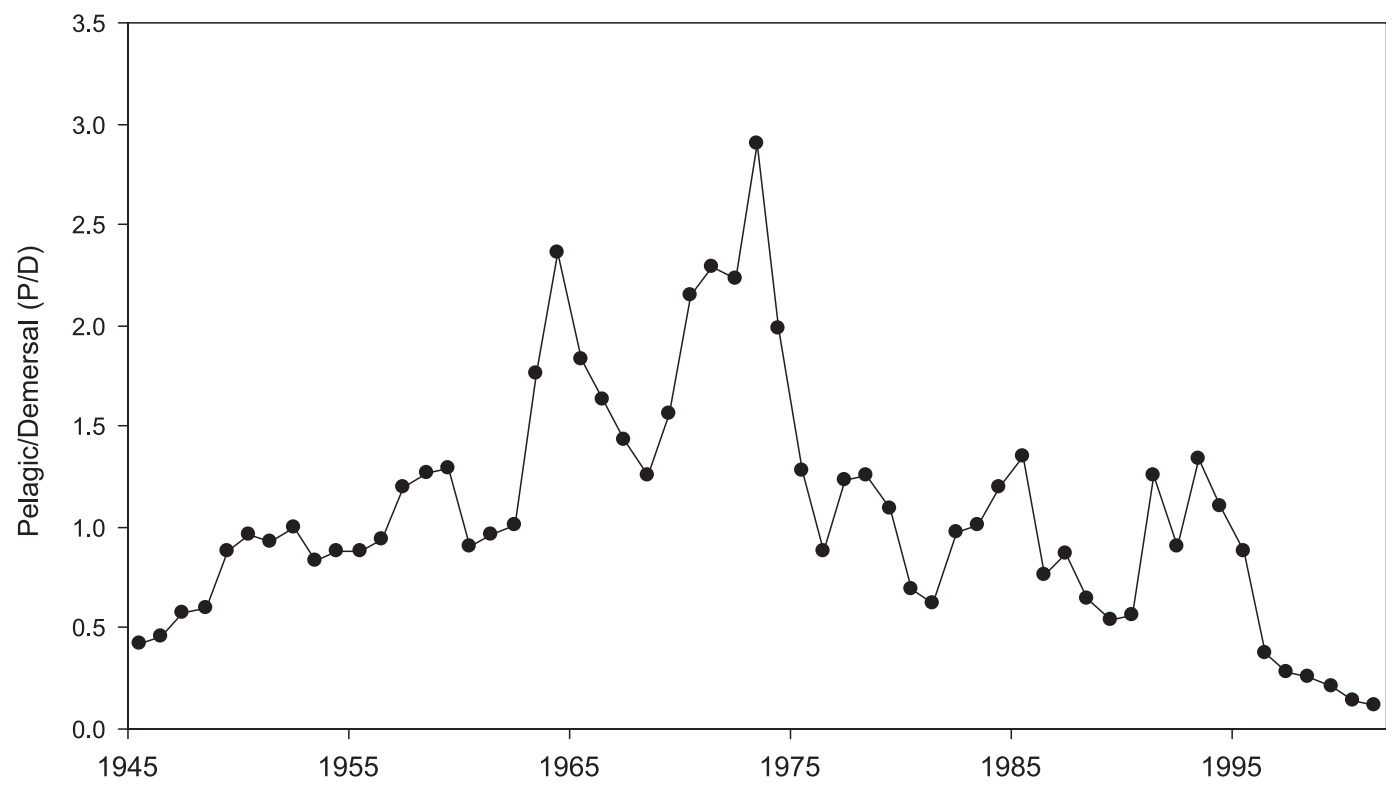

Fig. 4. Pelagic and demersal landings ratio (P/D ratio), which was estimated for the Venice Lagoon as the ratio between landings of the plankton feeders group and landings of the predators and benthic groups. 
the two factors. Furthermore, the slight increase in the mTL (Fig. 1) would seem to suggest that the effects of acute eutrophication or increasing fishing pressure in this period were not stressing the lagoon community. However, the analysis of the P/D ratio (Fig. 4), which is characterised by a positive trend in those years, suggests that during this phase the system has been subjected to a typical bottom-up control due to the increase in the DIP and DIN concentrations, which led to a predominance of the planktonic food web over the benthic one. In fact, the positive trend of the total landings in this first period was due primarily to the increase in the catches of plankton feeder species, namely Atherina boyeri, Engraulis encrasicolus and $S$. sprattus (Fig. 5). The lack of systematic data concerning DIN and DIP concentrations in the lagoon during those years does not allow for a direct testing of this hypothesis, but it is consistent with the results presented in Pastres et al. (2004) and with the findings given by Cossu and De Fraja Frangipane (1985), who report a 30-fold increase of phosphorus content in the sediment for the same period of time.

Furthermore, such hypothesis seems to be supported by the relatively high value of TE estimated for the sub-period 1962-1973, equal to $16 \%$ (Fig. $3 \mathrm{~B})$, which is in agreement with the predominance of the planktonic food web, more efficient than those sustained by benthic producers.
The increase in the fishing capacity, which resulted from to the introduction of engine-powered boats in the entire lagoon fleet (ISTAT, 1964-1993; Mozzi, 1967; data not shown), led to a progressive increase in the fishing effort, since the lagoon continued to be the target area of the traditional fishing activities. However, the time series of the landings and their mTL do not reveal noticeable overfishing effects in the period 1945-1973. Therefore, we can conclude that the augmented fishing effort was compensated by the rise in the lagoon production, due to the nutrient enrichment.

\subsection{The crisis of the lagoon landings}

The mTL was still on the increase after the year 1975, when a severe drop of the landings was recorded (Fig. 1), accompanied by a strong decrease in the $\mathrm{P} / \mathrm{D}$ ratio, which fluctuated around 1 during the following period 1975-1995. However, the fact that the FiB index was almost stable (Fig. 3A) and that the trend in the mTL was still positive suggests that overfishing was not the cause of the collapse of the landings.

Such evolution would suggest that, after the middle of the 1970s and over the 1980s, DIN and DIP concentrations were diminishing: the decrease of plankton feeders, trough bottom-up effect, is

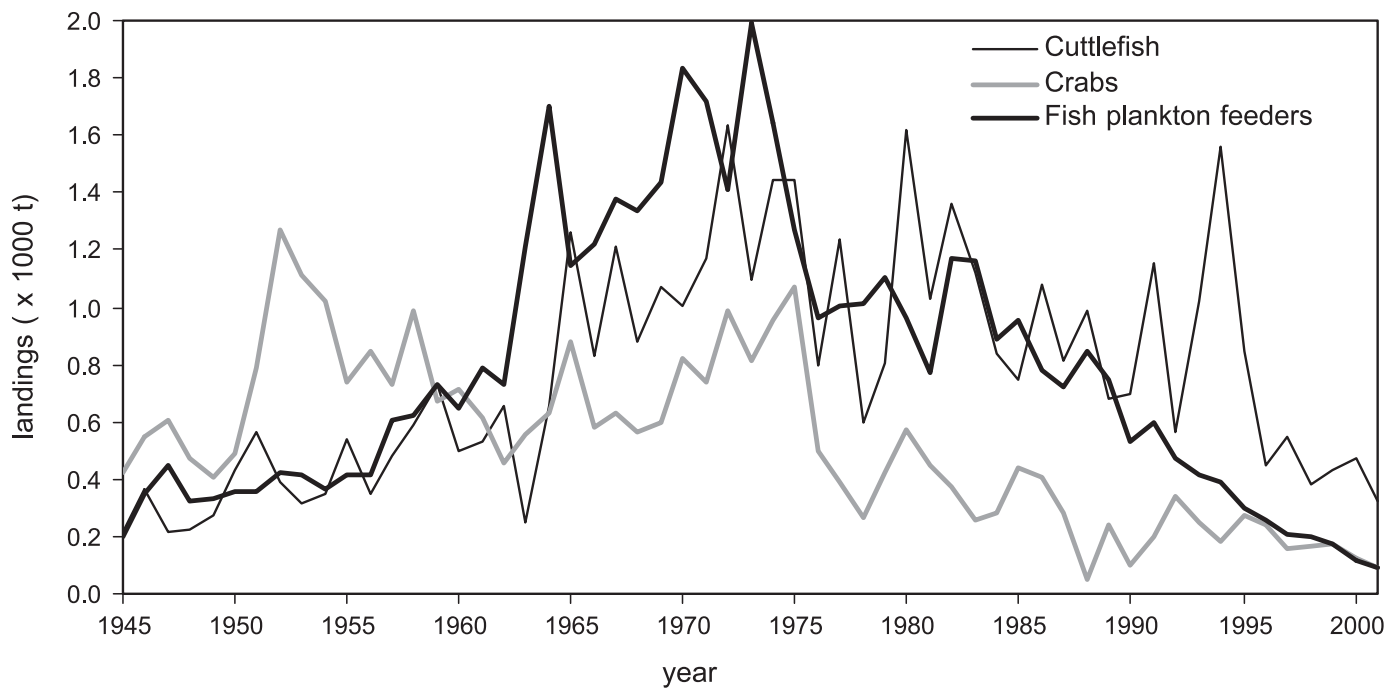

Fig. 5. Time series of landings of the plankton feeders, crabs and cuttlefish, grouped as specified in Table 1. 
interpreted as a signal of decreased primary planktonic production by reduction of nutrients availability as described for other ecosystems (Caddy, 1993, 2000; De Leiva Moreno et al., 2000).

In fact, over the first decade of this period, national and local regulations, together with management actions, such as the construction of waste-water treatment plants (Cossu and De Fraja Frangipane, 1985) led to a decrease of two order of magnitude in ammonium and phosphorus concentration in the lagoon of Venice (Pastres et al., 2004).

However, the decrease in the two main macronutrients did not occur simultaneously: as a result, the change in the N/P ratio may have been one of the causes of the shift in the primary production from the water column (phytoplankton) to the bottom (macroalgae) which was observed during the second half of the eighties (Sfriso et al., 1989). Macroalgae were less palatable for grazers (Sfriso and Marcomini, 1997; Flindt et al., 1997) and, therefore, their massive blooms (Sfriso et al., 1989) led to the segregation of energy from the trophic web. Furthermore, the macroalgae respiration markedly affected the oxygen balance, causing ipoxia and/or anoxia and the production of sulphides in the benthic layer (Cossu and De Fraja Frangipane, 1985). The repeated dystrophic crises, which were observed during the second half of the 1980 s, induced stress in the benthic communities, enhanced the accumulation of organic matter in the bottom sediments and caused a dramatic decrease in the seagrass meadow extension.

Accordingly to the so-called Marine Catchment Basin paradigm (Caddy, 1993, 2000), in eutrophicated ecosystem, a further increase of the nutrient loads induces an increase in the biomasses of those widetrophic spectrum species which are greatly resistant to oxygen depletion, such as jellyfish (Kideys, 2002) or, in some cases, cuttlefish and squids (Caddy, 1993). This stage could be recognized also in the Venice Lagoon that, after a decrease in the nutrient loads, was experiencing macroalgal blooms and dystrophic crises: as one can see from Fig. 5, the collapse in crab and plankton-feeder landings is observed in 1975, while cuttlefish remained an important fraction of the landings up to the beginning of the 1990s.

The trend of the TE is also consistent with the evolution of the eutrophication outlined above, as a low efficiency $(\mathrm{TE}=0.5 \%)$ was estimated for the
1974-1989 phase, see Fig. 3B. In fact, such value is consistent with the series of dystrophic crises, together with the low energy availability in the system, due to the presence of huge macroalgae biomass.

\subsection{Intensive exploitation of T. philippinarum}

The non-native clam, T. philippinarum, was introduced in the Venice Lagoon in 1983, in order to enhance the lagoon aquaculture production (Cesari and Pellizzato, 1985). This species, which is fast growing and a filter feeder with wide trophic spectrum (Sorokin and Giovanardi, 1995), resulted to be 'the right species at the right time' and it quickly colonized the whole lagoon, becoming an important economic resource: the maximum production, $60 \times 10^{6} \mathrm{~kg}$ year $^{-1}$ (total wet weight) was recorded in 1999 (Provincia di Venezia, 1999; Granzotto et al., 2001). As one can see from Fig. 1, in a few years, this species became the main target species for a new fishery operating in the lagoon. Manila clam accounted for up to $90 \%$ of the landings in the years $1992-1999$. In this period, a remarkable decrease in macroalgae biomass was observed and macroalgal blooms did not occur. Moreover, the expected shift, back to phytoplankton-based trophic web, was not detected, probably due to the grazing activity of the large stock of Manila clam.

The TE estimated for the sub-period 1990-1996 (equal to $20.0 \%$ ), represents an extreme value concerning the Transfer Efficiency of a given marine system, since Pauly and Christensen (1995) estimated for different marine ecosystems values ranging from $5 \%$ up to $20 \%$, with a mean value of $10 \%$. This could be related to the contribution made by the very productive Manila clam, which allowed for a better exploitation of the energy that had been buried into the bottom sediment during the previous period of low fishing production.

\subsection{A "fishing down food web" effect in the Venice Lagoon?}

The heavy exploitation of the Manila clam stock produced a decrease in the mTL in the period 19901996. However, the plot of mTL versus catches does not show a backward-bending curve till 1998 (Fig. 2, 
solid circles) and, therefore, a FDFW effect (Pauly et al., 1998) cannot be identified before this year.

However, a backward bending shape, noticeable in the plot of landings and mTL for artisanal fishery only (Fig. 2, open circles), allows detecting a sign of crisis for this fishery since 1995. This appears to be in accordance with the $\mathrm{FiB}$, which, although the landings quantities were very high, showed a steeper decreasing trend from 1995 to 2001 (Fig. 3A).

When it is taken into consideration that the traditional activity fishing effort had remained nearly constant over the last 30 years (ISTAT, 1964-1993; Mozzi, 1967), it raises that the clear sign of 'fishing down the lagoon trophic web' could not be the result of overfishing by this fishery. On the contrary, the decrease in landings and mTL for artisanal fishery must be interpreted as the effects, on the whole ecosystem, of the mechanical clam harvesting: the direct and indirect impacts produced a shift of the system that mimes the overfishing effects. Therefore, we can conclude that, on the basis of the analysis of the mTL and landings, the indirect effects of mechanical clam harvesting on the lagoon ecosystem became unsustainable since the 1995 .

\section{Conclusions}

The Venice Lagoon, a semi-enclosed basin subjected to different kinds of anthropogenic pressure, represents a very interesting case study, for the application of recent theories concerning the analysis of the time-series of the landings and of their mean Trophic Level. The results, and the discussion that followed, indicate that the analysis here presented provides a coherent picture of the successional stages of the ecosystem induced by different levels and/or causes of disturbances, identified as the nutrient enrichment and fishing pressure. The landings data provided an interesting way of studying the dynamic of the ecosystem and allowed for the identification of four stages, which are similar to those considered typical of exploited marine systems subjected to nutrient enrichment (Caddy, 1993; Cloern, 2001).

In fact, in our case, the landings could be considered as a representative way of sampling the lagoon fish and invertebrate communities. Furthermore, the analysis of the landings and their mean trophic level
(Pauly et al., 1998) proved to be useful also for interpreting the evolution of an estuarine system such as the Venice Lagoon. Using the landing data, we calculated a series of indicators, which gave estimates of both the impact of the fishing activity and the effects of nutrient enrichment on the ecosystem dynamic.

The increase in the landings after the Second World War were related to the joint effects of the growth of the fishing effort and, in particular till 1973, in the loads of dissolved nitrogen and phosphorus from the drainage basin (Cossu and De Fraja Frangipane, 1985). This nutrient loads sustained the productivity of some target species and allowed for intensive exploitation without producing any overfishing effects, since no collapse of the mTL was observed before the year 1990 .

The analysis of the time series of the landings showed a FDWF effect in the last part of the time series, clearly identifiable from 1995 using artisanal landings. The data of the fishing effort of the traditional fishing activity allowed for the exclusion of overfishing. The indirect effects of the mechanical harvesting of the Manila clam produced the FDFW observed in the artisanal landings.

Although the nutrients in the last decade (19902001) seem showing similar ratio characterizing the first expanding phase, 1945-1975 (Pastres et al., 2004), there is no evidence of increasing landings of plankton feeders. This is probably related to the high grazing activity of the Manila clam stock, thus competing with the other planktivores.

The estimations of TE were found to be consistent with the dynamics identified. Values of TE for the Venice Lagoon had been previously obtained from mass-balance models of the lagoon trophic web (Pranovi et al., 2003): TE ranged between $8.4 \%$ in 1988 , before T. philippinarum had become a target species, and $14.5 \%$ in 1998 , when the massive exploitation had occurred. The above values are not directly comparable with those estimated with the method used here, which provided a mean TE value for longer periods. However, the trend was corroborated, since both methods led to the estimation of lower values of TE during the 1980s and higher ones in the 1990s, after the exploitation of T. philippinarum had begun.

The negative trend observed in both the landings of artisanal fishery and their mTL from 1995 to 2001 has 
highlighted the need for a sustainable form of management concerning the Manila clam fishery. To this regard, the classical approach, namely the search for reference points, may not be sufficient, since it does not take into account the indirect effects of this type of fishing activity nor the variability in primary production. These considerations provide even more evidence of the need for both an ecosystem-based and a precautionary approach to the fishery management, in order to better define the alternatives and assess the sustainability of the fishery.

\section{Acknowledgements}

The authors are particularly grateful to Daniel Pauly and Yvette Rizzo of the Fisheries Centre, University of British Columbia (Vancouver, Canada), for their suggestions, advice and discussion during the early phases of this work. Moreover, a revised version of this paper benefited from the corrections given by Pablo Trujillo. We would also like to thank the two anonymous referees for their constructive comments, which led to improve the quality of this paper. This work was funded by CORILA.

\section{References}

Arias, A., 1980. Crecimiento, regimen alimentario y reproduccion de la dorada (Sparus aurata L.) y del robalo (Dicentrarchus labrax L.) en los esteros de Cadiz. Investigación Pesquera 44 (1), 59-83.

Azienda Speciale Acquacoltura e Pesca di Venezia (ASAP), 1999. Studio per la razionalizzazione delle attività di pesca e di molluschicoltura nel bacino di Chioggia, laguna di Venezia. ASAP, Venice, p. 54.

Caddy, J.F., 1993. Toward a comparative evaluation of human impacts on fishery ecosystems of enclosed and semi-enclosed seas. Reviews in Fisheries Science 1, 57-95.

Caddy, J.F., 2000. Marine catchment basin effects versus impacts of fisheries on semi-enclosed seas. ICES Journal of Marine Science 57, 628-640.

Caddy, J.F., Csirke, J., Garcia, S.M., Grainger, R.J.R., 1998. How pervasive is "fishing down marine food webs"? Science 282, 1383a.

Cesari, P., Pellizzato, M., 1985. Molluschi pervenuti in laguna di Venezia per apporti antropici volontari o casuali. Acclimazione di Saccostrea commercialis (Iredale e Rougley, 1933) e di Tapes philippinarum (Adams e Reeve, 1850). Bollettino Malacologico 21, 237-274.
Christensen, V., Pauly, D. (Eds.), 1993. Trophic Models of Aquatic Ecosystems. ICLARM Conf. Proc., vol. 26, p. 390.

Cloern, J.E., 2001. Our evolving conceptual model of the coastal eutrophication problem. Marine Ecology Progress Series 210, $223-253$.

Cossu, R., De Fraja Frangipane, E., 1985. Stato delle conoscenze sull'inquinamento della laguna di Venezia. Consorzio Venezia Nuova, Venice (Vol. I-IV), 438 pp.

Costa, J.L., Assis, C.A., Almeida, P.R., Moreira, F.M., Costa, M.J., 1992. On the food of the European eel, Anguilla anguilla (L.), in the upper zone of the Tagus estuary, Portugal. Journal of Fish Biology 41, 841-850.

Da Ponte, F., Raicevich, S., Pranovi, F., Franceschini, G., Boscolo, R., Giovanardi, O., 2001. A multidisciplinary study of the effects of mechanical clam harvesting on benthic compartment in the Venice Lagoon. 36th European Marine Biology Symposium, Menorca, Spain.

De Leiva Moreno, J.I., Agostani, V.N., Caddy, J.F., Carocci, F., 2000. Is the pelagic-demersal ratio from fishery landings a useful proxy for nutrient availability? A preliminary data exploration for the semi-enclosed seas around Europe. ICES Journal of Marine Science 57, 1091-1102.

Desrosiers, G., Bellan-Santini, D., Brêthes, J.C., 1986. Organisation trophique de quatre peuplements de substrats rocheux selon un gradient de polution industrielle (Golfe de Fos, France). Marine Biology 91, 107-120.

Desrosiers, G., Savenkoff, C., Olivier, M., Stora, G., Juniper, K., Caron, A., Gagnè, J.-P., Legendre, L., Mulsow, S., Grant, J., Roy, S., Grehan, A., Scaps, P., Silverberg, N., Klein, B., Tremblay, J.-E., Therriault, J.C., 2000. Trophic structure of macrobenthos in the Gulf of St. Lawrence and on the Scotian Shelf. Deep-Sea Research 47, 663-697.

DRAIN, 2001. Determination of the pollutant load discharged into the Venice Lagoon by the drainage basin. Discussion and presentation of the methods and the main results of the DRAIN project. Ministro dei Lavori Pubblici-Magistrato alle acque, Consorzio Venezia Nuova. CNR, Venice, p. 111.

Fauchauld, K., Jumars, P.A., 1979. The diet of worms: a study of polychaete feeding guilds. Oceanography and Marine Biology: An Annual Review 17, 193-284.

Flindt, M., Salomonsen, J., Carrer, M., Bocci, M., Kamp-Nielsen, L., 1997. Loss, growth and transport dynamics of Chaetomorpha aerea and Ulva rigida in the Lagoon of Venice during early summer field campaign. Ecological Modelling 102, $133-141$.

Froese, R., Pauly, D. (Eds.), 2002. FishBase. www page, http:// www.fishbase.org.

Granzotto, A., Franzoi, P., Longo, A., Pranovi, F., Torricelli, P., 2001. La pesca nella laguna di Venezia: un percorso di sostenibilità nel recupero delle tradizioni:lo stato dell'arte. Rapporto Sullo Sviluppo Sostenibile 2, 1-61.

ISTAT, 1964-1993. Annuario statistico della pesca e della caccia ISTAT, Rome (29 volumes)

Jackson, J.B.C., Kirby, M.X., Berger, W.H., Bjorndal, K.A., Botsford, L.W., Bourque, B.J., Bradbury, R.H., Cooke, R., Erlandson, J.A., Estes, J.A., Hughes, T.P., Kidwell, S., Lange, C.B., Lenihan, J.M., Pandolci, J.M., Peterson, C.H., Steneck, R.S., Tegner, M.J., 
Warner, R.R., 2001. Historical overfishing and the recent collapse of coastal ecosystems. Science 293, 629-638.

Jennings, S., Kaiser, M.J., 1998. The effects of fishing on marine ecosystems. Advances in Marine Biology 34, 201-351.

Kideys, A.E., 2002. Fall and rise of the Black Sea ecosystem. Science 297, 1482-1484.

Libralato, S., Pastres, R., Pranovi, F., Raicevich, S., Granzotto, A., Giovanardi, O., Torricelli, P., 2002. Comparison between the energy flow networks of two habitats in the Venice Lagoon. Marine Ecology 23, 228-236.

Lindeman, R.L., 1942. The trophic-dynamic aspect of ecology. Ecology 23, 399-418.

Mainardi, D., Fiorin, R., Franco, A., Franzoi, P., Giovanardi, O., Granzotto, A., Libertini, A., Malavasi, S., Pranovi, F., Riccato, P., Torricelli, P., 2002. Fish diversity in the Venice Lagoon: preliminary report. In: Campostrini, P. (Ed.), Scientific Research and Safeguarding of Venice (Corilla Research Program 2001 Results), Instituto Veneto di Scienze Lettere ed Arti. La Garangola, Paolova, vol. 51-52, pp. 583-594.

Mozzi, C., 1967. Notizie sulla flotta di Chioggia e Venezia. Archivio di Oceanografia e Limnologia 15, 245-286.

Palomares, M.L.D., Reyes-Marchant, P., Lair, N., Zainure, M., Barnabe, G., Lassarre, G., 1993. A trophic model of a Mediterranean Lagoon, Etang de Thau, France. In: Pauly, D., Christensen, V. (Eds.), Trophic Models of Aquatic Ecosystems. ICLARM Conf. Proc., vol. 26, pp. 224-229.

Pastres, R., Solidoro, C., Ciavatta, S., Petrizzo, A., Cossarini, G., 2004. Long-term changes of inorganic nutrients in the Lagoon of Venice (Italy). Journal of Marine Systems 51, 179-189 this issue.

Pauly, D., Christensen, V., 1995. Primary production required to sustain global fisheries. Nature 374, 255-257.

Pauly, D., Palomares, M.L., 2000. Approaches for dealing with three sources of bias when studying the fishing down marine food web phenomenon. CIESM Workshop Series 12, 61-66.

Pauly, D., Palomares, M.L., 2004. Fishing down marine food web: it is far more pervasive than we thought. Bulletin of Marine Science 74/3(S) (in press).

Pauly, D., Christensen, V., Dalsgaard, J., Froese, R., Torres Jr., F. 1998. Fishing down marine food webs. Science 279, 860-863.

Pauly, D., Christensen, V., Walters, C., 2000a. Ecopath, Ecosim, and Ecospace as tools for evaluating ecosystem impacts on marine ecosystems. ICES Journal of Marine Science 57, 697-706.

Pauly, D., Froese, R., Sa-a, P.S., Palomares, M.L., Christensen, V., Rius, J., 2000b. TrophLab Manual ICLARM, Manila, Philippines.
Pauly, D., Palomares, M.L.D., Froese, R., Sa-a, P., Vakily, M., Preikshot, D., Wallace, S., 2001. Fishing down Canadian aquatic food webs. Canadian Journal of Fisheries and Aquatic Sciences $58,51-62$.

Pinnegar, J.K., Polunin, N.V.C., 1999. Differential fractionation of d13C and d15N among fish tissue: implication for the study of trophic interactions. Functional Ecology 13, 225-231.

Pinnegar, J.K., Jennings, S., O’Brien, C.M., Polunin, N.V.C., 2002. Long-term changes in the trophic level of the Celtic Sea fish community and fish market price distribution. Journal of Applied Ecology 39, 377-390.

Polunin, N.V.C., Pinnegar, J.K., 2000. Trophic-level dynamics inferred from stable isotopes of carbon and nitrogen. CIESM Workshop Series 12, 69-72.

Pranovi, F., Giovanardi, O., 1994. The impact of hydraulic dredging for short-necked clams, Tapes spp., on an infaunal community in the lagoon of Venice. Scientia Marina 58 (4), 345-353.

Pranovi, F., Libralato, S., Raicevich, S., Granzotto, A., Pastres, R., Giovanardi, O., 2003. Mechanical clam dredging in Venice Lagoon: ecosystem effects evaluated with a trophic mass-balance model. Marine Biology 143, 393-403.

Provincia di Venezia, O., 1999. . Piano per la gestione delle risorse alieutiche delle lagune della provincia di Venezia. Provincia di Venezia, Venice, pp. 1-50.

Sfriso, A., Marcomini, A., 1997. Macrophyte production in a shallow coastal lagoon: Part II. Coupling with chemico-physical parameters and nutrient concentrations in waters. Marine Environmental Research 44, 351-375.

Sfriso, A., Pavoni, B., Marcomini, A., 1989. Macroalgae and phytoplankton standing crops in the central Venice Lagoon: primary production and nutrient balance. Science of the Total Environment 80, 139-159.

Solidoro, C., Pastres, R., Melaku Canu, D., Pellizzato, M., Rossi, R., 2000. Modelling the growth of Tapes philippinarum in northern Adriatic lagoons. Marine Ecology Progress Series 199, 137-148.

Sorokin, Y.I., Giovanardi, O., 1995. Trophic characteristics of the Manila clam (T. philippinarum Adams \& Reeve, 1850). ICES Journal of Marine Science 52, 853-862.

Stergiou, K.I., Karpouzi, V.S., 2002. Feeding habits and trophic levels of Mediterranean fish. Reviews in Fish Biology and Fisheries 11, 217-254.

Stergiou, K.I., Koulouris, M., 2000. Fishing down the marine food webs in the Hellenic seas. CIESM Workshop Series 12, 73-78.

Watson, R., Pauly, D., 2001. Systematic distortions in world fisheries catch trends. Nature 414, 534-536. 